\title{
ELASTISITAS PENDAPATAN WAJIB PAJAK (ELASTICITY OF TAXABLE INCOME) DI INDONESIA
}

\author{
Arif Nugrahanto \\ Politeknik Sekolah Tinggi Akuntansi Negara \\ arifnugrahanto1980@gmail.com
}

\begin{abstract}
The responses of taxpayers due to the changes in tax rates have attracted the curiosity of many economists. The magnitude of taxpayers' responses is substantially considered to be very importance in the formulation of tax and transfer policy (Giertz, 2009). The fundamental analysis on how to see the respond of taxpayers due to any changes in tax rates uses elasticity of labor supply, which estimates the changes of working hours with respect to the changes in tax rates. Because people's response to a tax change may take several forms, including a labor supply response, elasticity of labor supply must be read carefully, as pertaining only to specific circumstances. Then, the elasticity of taxable income, which was originated by Lindsey (1986), is used and introduced to overcome such restrictions.

Using very rich panel data of Indonesian taxpayers from 2007 to 2010, this study generates numerous findings about the elasticity of taxable income. The extent of taxpayers' response deeply depends on how the secular trend of income is isolated and controlled. Without income control, the elasticity of taxable income is 0.289, while using a 10-spline of log of income, the extent is 0.368. Moreover, the study also uses net income as complement of the core estimation.

This study identifies that the elasticity of taxable income in Indonesia is in the range of 0.302-0.368 depending on the income definition applied. The findings confirm with most literature on this subject and closely near to what was specified by Saez, et. al (2010) as "a consensus value." But it should be underlined that these magnitudes are just in the short run period. This also found that the short run and medium period produce varying magnitudes. The medium run period calculation generates the number of close to zero. It might be due to the existence of income shifting, as stated by Goolsbee (2000). Another argument is myopic phenomenon. As taxpayers only focus on the situation that just happen surroundings them.

The difference in the effect highpoints what Slemrod (2001) said that the magnitude of reported income elasticity is not an unchanged parameter; indeed, it is subject to government policy. Moreover, the surroundings of the tax reform and after all may also have influences.
\end{abstract}

Keywords: Elasticity of Taxable income, Taxpayers' Responses, Changes of tax rate, Indonesia.

\section{PENDAHULUAN}

Respon Wajib Pajak terhadap perubahan tarif pajak telah menarik perhatian para ekonom. Besar-kecilnya respon Wajib Pajak tersebut dianggap sebagai hal yang sangat substansial atau penting dalam proses formulasi kebijakan perpajakan (Giertz, 2009). Teori dasar yang menjadi pijakan dalam analisis mengenai respon Wajib Pajak terhadap adanya perubahan tarif $\mathrm{PPh}$ 
adalah elastisitas labor supply, yang mengestimasi perubahan jam kerja (working hours) akibat adanya perubahan tarif pajak. Namun, mengingat elastisitas labor supply merupakan akumulasi dari adanya perubahanperubahan yang melibatkan banyak faktor, maka penggunaan elastisitas labor supply dalam analisis kebijakan pajak dan secara khusus yang terkait dengan respon Wajib Pajak, perlu dilakukan secara hati-hati dengan memperhatikan situasi dan kondisi tertentu.

Untuk mengatasi keterbatasan elastisitas labor supply dalam mengestimasi perubahan respon Wajib Pajak, maka Linsey (1986) memperkenalkan elasticity of taxable income yang selanjutnya disebut elastisitas pendapatan. Besaran elatisitas ini dapat diartikan sebagai persentase perubahan penghasilan atau pendapatan yang dilaporkan di SPT (reported income) yang disebabkan adanya perubahan tarif pajak (marginal net-of-tax rate). Mengingat secara prinsip elastisitas pendapatan ini dapat menghimpun seluruh respon Wajib Pajak, Saez, et.al (2010) menyatakan bahwa elastisitas ini menjanjikan estimasi marginal efficiency cost of taxation yang lebih akurat.

Pada tahun 2008, Pemerintah Republik Indonesia melaksanakan reformasi perpajakan. Berbeda dengan reformasi perpajakan sebelumnya yang biasanya malah menaikkan tarif pajak, reformasi perpajakan tahun 2008 justru menurunkan tarif $\mathrm{PPh}$, beserta penyederhanaan jumlah lapisan tarif $\mathrm{PPh}$. Wajib Pajak yang memiliki pendapatan Rp200 juta sampai dengan Rp250 juta mendapatkan keuntungan yang paling signifikan dibandingkan Wajib Pajak pada lapisan pendapatan yang lainnya. Wajib Pajak yang berada pada lapisan tarif ini menikmati penurunan tarif pajak sebesar 20 basis poin (percentage points). Lebih lanjut, bagi Wajib Pajak yang berada di posisi teratas (the top income earners) juga mendapatkan keuntungan berupa penurunan tarif pajak sebesar 5 basis poin, yaitu dari $35 \%$ menjadi $30 \%$.

Dalam analisis ekonomi, situasi tahun 2008 tersebut dapat digunakan sebagai eksperimen alamiah (natural experiment). Perubahan tarif pajak yang signifikan tersebut dapat dijadikan sebagai laboratorium untuk menguji suatu kebijakan pemerintah. Dalam hal ini, adanya penurunan tarif pajak tersebut 
dapat dijadikan sebagai alat untuk mengetahui bagaimana perilaku atau reaksi Wajib Pajak. Apakah Wajib Pajak akan meningkatkan nilai pendapatan yang dilaporkan pada SPT sebagaimana harapan pemerintah atau justru malah sebaliknya. Memanfaatkan situasi tersebut, penelitian ini mencoba mengcapture ada-tidaknya perubahan perilaku atau respon Wajib Pajak yang disebabkan adanya perubahan tarif pajak, yang dalam hal ini perubahan tarif $\mathrm{PPh}$, dengan menghitung atau mengestimasi secara statistik nilai elastisitas pendapatan.

Penelitian ini memperkaya literatur empiris, khususnya di bidang perpajakan yang terkait dengan perubahan perilaku Wajib Pajak yang diakibatkan oleh suatu kebijakan pemerintah. Dengan mengetahui elastisitas pendapatan Wajib Pajak maka kita dapat mengidentifikasi sebesaran besar peningkatan atau penurunan penghasilan yang dilaporkan dalam SPT akibat adanya perubahan tarif PPh yang terjadi pada tahun 2008. Dengan mengetahui hal tersebut, maka temuan penelitian ini dapat digunakan sebagai referensi dalam memformulasikan kebijakan-kebijakan perpajakan, khususnya yang trekait dengan isu penaikan atau penurunan tarif $\mathrm{PPh}$.

\section{METODOLOGI PENELITIAN}

Penelitian ini menggunakan pendekatan kuantitatif. Model penelitian mengadopsi penelitian yang dilakukan oleh Gruber and Saez (2002) dengan penyesuaian objek penelitian di Indonesia. Data yang digunakan adalah data SPT PPh Orang Pribadi yang dimiliki oleh Direktorat Jenderal Pajak, dua tahun sebelum adanya reformasi perpajakan 2008, yaitu data SPT Tahun Pajak 2007 dan 2008, dan dua tahun setelah adanya reformasi perpajakan 2008, yaitu data SPT PPh Orang Pribadi Tahun Pajak 2009-2010.

\section{HASIL PENELITIAN DAN PEMBAHASAN}

\section{a. Pajak Penghasilan di Indonesia}

Pajak Penghasilan $(\mathrm{PPh})$ merupakan sumber penerimaa negara yang paling besar bagi pemerintah Indonesia. Dalam beberapa tahun terakhir, 
tercatat lebih dari 50\% penerimaan negara ditopang dari penerimaan pajak, khususnya PPh. Sedemikian pentingnya dalam membiayai pengeluaran pemerintah, maka ketentuan mengenai perpajakan di Indonesia menjadi ketentuan hokum yang paling dinamis. Tak kurang dalam 20 tahun terakhir, telah terjadi lima kali reformasi perpajakan, antara lain pada tahun 1983, 1991, 1994, 2000, dan terakhir 2008.

Sejak tahun 1983, pemerintah Indonesia menerapkan self-assessment system sebagai prinsip dasar dalam pemungutan pajak di Indonesia setelah sebelumnya menerapkan official assessment. Sebagai basis pemajakan, Indonesia menerapkan family based, bukan individual based, sehingga satu keluarga cukup memiliki satu nomor pokok dan satu pelaporan pajaknya. Dengan demikian, laki-laki dan perempuan yang menikah, cukup memiliki satu buah Nomor Pokok Wajib Pajak untuk mengadministrasikan kewajiban perpajakannya. Namun dalam reformasi perpajakan yang terakhir, terdapat kelonggaran dalam penerapan family-based principle ini. Wanita yang memiliki penghasilan, dapat meminta otoritas perpajakannya supaya dipisah administrasi perpajakannya dengan keluarga atau suaminya.

Dalam menghitung kewajiban PPh, setiap Wajib Pajak secara umum harus melakukan empat langkah penghitungan. Pertama, Wajib Pajak harus mengumpulkan seluruh penghasilan yang dia peroleh dalam suatu tahun pajak, baik penghasilan dia sendiri maupun penghasilan anggota keluarganya. Baik yang berasal dari Indonesia maupu dari luar Indonesia, baik yang berasal dari active income maupun passive income. Semua harus dikumpulkan dan dihitung secara agregat. Total penghasilan ini dalam SPT dituangkan pada kolom Penghasilan Bruto. Setelah diketahui penghasiulan bruto, Wajib Pajak diperbolehkan melakukan penyesuaian atas beberapa pos pengeluaran yang diperbolehkan, antara lain pengeluaran untuk BPJS Ketenagakerjaan (pension plan). Hasil dari penyesuaian ini menghasilkan Penghasilan Bersaih, yang di dalam banyaj literatur mengenai subjek dalam penelitian ini, disebut juga adjusted gross income. 
Langkah berikutnya adalah menyesuaikan penghasilan bersih tersebut dengan biaya hidup, yang dalam UUPPh disebut Penghasilan Tidak Kena Pajak (PTKP). PTKP maksimal yang ditanggung atau diperbolehkan oleh pemerintah adalah 1 orang istri dengan 3 orang tanggungan. Lebih dari itu maka pemerintah tidak memperbolehkan pengeluaran biaya hidupnya sebagai pengurang penghasilan bersih. Hasil dari penyesuaian biaya hidup ini menghasilkan jenis penghasilan yang disebut penghasilan kena pajak (taxable income). Penghasilan kena pajak inilah yang menjadi dasar perhitungan pajak yang harus dibayar oleh Wajib Pajak. Dalam penelitian ini, definisi penghasilan inilah yang digunakan dalam melakukan estimasi elastisitas pendapatan.

Langkah ketiga adalah menghitung kewajiban $\mathrm{PPh}$. Langkah ini dilakukan dengan cara mengkalikan tarif pajak $(\mathrm{PPh})$ dengan dasar pengenaan pajak, yang dalam hal ini adalah penghasilan kena pajak. Saat ini, berdasarkan reformasi perpajakan 2008, berlaku 4 lapisan tarif $\mathrm{PPh}$, dengan marginal tax rate pada lapisan pertama sebesar 5\%, kemudian berturut-turut sebesar 15\%, 25\%, dan 30\% yang diterapkan secara progresif berdasarkan besar-kecilnya penghasilan kena pajak.

Langkah terakhir setelah mengetahui kewajiban pajak (PPh) tersebut adalah memperhitungkan dengan kredit pajak yang dipotong oleh pihak lain, kemudian membayar PPh yang tersisa ke kas negara dan terakhir melaporkan ke otoritas pajak dengan menggunakan formulir yang disebut SPT PPh Orang Pribadi.

\section{Reformasi Perpajakan 2008}

Pada tahun 2008, pemerintah Indonesia memberlakukan UndangUndang Pajak Penghasilan (UUPPh) yang baru, yang merupakan penyempurnaan dari UU PPh yang lama. Tujuan utama pemberlakuan ini adalah untuk meningkatkan tax ratio, peningkatan penerimaan pajak secara agregat, yang selama ini memang termasuk dalam kategori rendah dibandingkan dengan negara-negara se-kawasan. 
Menurut pemerintah, sistem pajak yang berlaku dan yang sedang diterapkan oleh pemerintah masih dianggap rumit dan kompleks. $1 \mathrm{Hal}$ ini terlihat dari tingginya marginal tax rate, hingga mencapai 35\% dan rendahnya basis data untuk pemajakan. Tingginya tarif pajak ini mendorong orang-orang untuk melakukan penghindaran pajak, yang dibuktikan dengan rendahnya kesadaran WAjib Pajak melakukan pelaporan kewajiban perpajakannya. Tahun 2008 jumlah Wajib Pajak yang melaporkan SPT hanya berada pada kisaran 33\% dari total NPWP terdaftar.2

Memahami situasi ini maka pemerintah melakuakn reformasi perpajakan pada tahun 2008. Beberapa atribut reformasi perpajakan tersebut yang paling terlihat adalah munculnya definisi penghasilan yang dimunculkan dalam UUPPh. Hal ini dianggap sebagai upaya untuk mempertegas dan memperjelas jenis-jenis penghasilan yang dapat menjadi objek pajak sehingga mengurangi dispute atau kebingungan di masyarakat. Isu lainnya adalah tentang pemberian donasi yang dijelaskan dalam penjelasan UUPPh secara jelas sehingga tidak multi-tafsir dan menjadi sumber sengketa yang tak berkesudahan dengan Wajib Pajak.

Diantara hal-hal tersebut, terdapat 3 aspek perubahan yang paling mencolok dari reformasi perpajakan tahun 2008. Pertama adalah adanya penurunan tarif pajak dan perluasan cakupan penghasilan dalam tiap-tiap lapisan tarif pajak. Tabel di bawah ini merangkum perubahan tarif pajak dan perluasan lapisan tarif pajak. 
Tabel 1

Perbandingan Lapisan Penghasilan (tax bracket) dan Tarif Pajak

\begin{tabular}{|c|l|c|l|c|}
\hline \multirow{2}{*}{ No } & \multicolumn{2}{|c|}{ Sebelum 2008 } & \multicolumn{2}{c|}{ Setelah 2008 } \\
\cline { 2 - 5 } & \multicolumn{1}{|c|}{ Lapisan Penghasilan } & $\begin{array}{l}\text { Marginal } \\
\text { Tax Rate }\end{array}$ & \multicolumn{1}{c|}{ Lapisan Penghasilan } & $\begin{array}{c}\text { Marginal } \\
\text { Tax Rate }\end{array}$ \\
\hline 1 & $\begin{array}{l}\text { Kurang atau sama } \\
\text { dengan Rp25 juta }\end{array}$ & $5 \%$ & $\begin{array}{l}\text { Kurang atau sama dengan } \\
\text { Rp50 juta }\end{array}$ & $5 \%$ \\
\hline 2 & $\begin{array}{l}\text { Penghasilan antara Rp25- } \\
50 \text { juta }\end{array}$ & $10 \%$ & $\begin{array}{l}\text { Penghasilan antara Rp50- } \\
\text { 250 juta }\end{array}$ & $15 \%$ \\
\hline 3 & $\begin{array}{l}\text { Penghasilan antara Rp50- } \\
100 \text { juta }\end{array}$ & $15 \%$ & $\begin{array}{l}\text { Penghasilan antara Rp250- } \\
500 \text { juta }\end{array}$ & $25 \%$ \\
\hline 4 & $\begin{array}{l}\text { Penghasilan antara } \\
\text { Rp100-200 juta }\end{array}$ & $25 \%$ & Lebih dari Rp500 juta & $30 \%$ \\
\hline 5 & Lebih dari Rp200 juta & & & \\
\hline
\end{tabular}

Sumber: UUPPh (UU Nomor 17 Tahun 2000 dan UU Nomor 36 Tahun 2008)

Berikutnya adalah kenaikan Penghasilan Tidak Kena Pajak (PTKP) yang memang telah lama ditunggu-tunggu oleh masyarakat. PTKP adalah fitur dalam UUPPh yang digunakan untuk menng-capture biaya hidup dalam perhitungan pajak penghasilan. Berdasarkan UUPPh 2008, terdapat kenaikan PTKP hingga 20\%, yaitu dari Rp13.200.000, - menjadi Rp15.840.000,- untuk Wajib Pajak dengan status single, belum menikah dan tidak mempunyai tanggungan. Secara lengkap, Tabel 2 berikut ini disajikan perbandingan PTKP antara UUPPh 2000 (sebelum reformasi 2008) dan UUPPh 2008 (reformasi perpajakan 2008).

Tabel 2

Perbandingan PTKP Sebelumd an Sesudah Reformasi Perpajakan 2008

\begin{tabular}{|c|l|c|c|}
\hline No & \multicolumn{1}{|c|}{ Status } & Sebelum 2008 & Sesudah 2008 \\
\hline 1 & Single & $13,200,000$ & $15,840,000$ \\
\hline 2 & $\begin{array}{l}\text { Tambahan bagi yang } \\
\text { menikah }\end{array}$ & $1,200,000$ & $1,320,000$ \\
\hline 3 & $\begin{array}{l}\text { Tambahan bagi suami/istri } \\
\text { yang bekerja }\end{array}$ & $13,200,000$ & $15,840,000$ \\
\hline 4 & $\begin{array}{l}\text { Tambahan untuk tiap } \\
\text { tanggunga, maksimal 3 } \\
\text { orang) }\end{array}$ & $1,200,000$ & $1,320,000$ \\
\hline
\end{tabular}

Sumber: UUPPh (UU Nomor 17 Tahun 2000 dan UU Nomor 36 Tahun 2008) 
Dan fitur terakhir tentang reformasi perpajakan 2008 adalah adanya formulir SPT PPh bagi orang pribadi yang dapat disesuaikan dengan jenis dan besaran penghasilan yang diperolehnya.

\section{b. Empirical Framework}

Model ekonomi yang menjadi dasar dalam melakukan estimasi elastisitas pendapatan adalah perluasan dari model static labor supply. Tiap individi akan berusaha memaksimalkan utilitasnya dengan fungsi utilitas $u(c, l)$, dimana $c$ merupakan disposable income, penghasilan yang dapat digunakan untuk konsumsi pada suatu periode waktu, dan $l$ yang merupakan ukuran labor supply yang dihitung dengan pendekatan working hour (jam kerja). Mengingat jumlah jam kerja yang merupakan bagian labor supply juga dipengaruhi oleh pajak penghasilan (Feldstein, 1995), maka. fungsi utilitas yang akan dipengaruhi secara positif oleh konsumsi (c) dan juga akan dipengaruhi secara negatif oleh penghasilan yang dilaporkan di SPT (reported income) yang dinotasikan sebagai $z$. Dengan demikian maka fungsi utilitas dapat disajikan sebagai fungsi dari konsumsi dan penghasilan yang dilaporkan di SPT oleh Wajib Pajak, $u(c, z)$.

Menurut Grube dan Saez (2002), untuk mengoptimalkan utilitas, orang akan memilih kombinasi antara $c$ dan $z$ dengan budget constraint $c=$ $z(1-\tau)+R$, dimana $z$ adalah penghasilan sebelum pajak, yang merupakan hasil kali dari working hour dengan tingkat gaji (wage rate), $z=w l$, dimana $w$ adalah wage rate.

$\tau$ adalah marginal tax rate dan $R$ adalah penghasilan virtual (virtual income). Optimalisasi ini menghasilkan persamaan fungsi an individual reported income supply function $z=z(1-\tau, R)$ dimana $z$ tergantung dari net-of-tax rate $1-\tau$ dan virtual income $R$ yang diperoleh dari tax/transfer system. Untuk seorang individu maka setiap perubahan pajak dapat ditranslete menjadi perubahan virtual income $R$ dan perubahan marginal tax rate $\tau$. Perubahan ini akan mempengaruhi the reported income supply function $z(1-\tau, R)$ sebagai berikut.. 


$$
d z=-\frac{\partial z}{\partial(1-\tau)} d \tau+\frac{\partial z}{\partial R} d R
$$

Gruber dan Saez (2002) memperkenalkan elastisitas pendapatan yang tak terkompensasi (uncompensated elasticity of income) terhadap net of tax rate yang dinotasikan sebagai $\zeta^{U}=\left[\frac{(1-\tau)}{z}\right] \partial z / \partial(1-\tau)$ dan income effect parameter dengan notasi sebagai $\eta=(1-\tau) \partial z / \partial R$ untuk memisahkan antara substitution effect dan income effect dalam model. Dengan mempertimbangkan dua efek ini dalam kalkulasi maka income supply $z$ menjadi sebagai berikut.

$$
d z=-\zeta^{U} z \frac{d \tau}{1-\tau}+\eta \frac{d R}{1-\tau}
$$

Dengan menggunakan compensated elasticity of income $\zeta^{C}=$ $\left[\frac{(1-\tau)}{z}\right] \partial z /\left.\partial(1-\tau)\right|_{U}$ dan mempertimbangkan Slutsky decomposition bahwa $\zeta^{C}=\zeta^{U}-\eta$, model ekonomi menjadi sebagai berikut:

$$
\frac{d z}{z}=-\zeta^{C} \frac{d \tau}{1-\tau}+\eta \frac{d R-z d \tau}{z(1-\tau)}
$$

dimana $d R-z d \tau$ merupakan perubahan income setelah pajak yang disebabkan karena adanya perubahan tarif pajak untuk tingkat pendapatan $Z$ dimana nilainya sama dengan perubahan $\mathrm{PPh}$ bagi Wajib Pajak dengan penghasilan $z$.

\section{Model Regresi}

Persamaan 1 di atas menunjukkan bahwa pendapatan yang dilaporkan si SPT akan berubah ketika terjadi perubahan tarif pajak $(d \tau, d R)$. Untuk menghitung perubahan tersebut, maka digunakan spesifikasi logaritma (loglog specification). Dengan menggunakan persamaan 1 dan logaritma natural arrangement maka $\frac{d z}{z}$ menjadi $\log \frac{z_{i t+1}}{z_{i t}}$. Kemudian untuk $\frac{d \tau}{1-\tau}$ menjadi 
$\log \frac{\left(1-\tau_{i t+1}\right)}{\left(1-\tau_{i t}\right)}$ sedangkan $\frac{d R-z d \tau}{z(1-\tau)}$ menjadi $\log \frac{\left[z_{i t+1}-T_{i t}\left(z_{i t+1}\right)\right]}{\left[z_{i t}-T_{i t}\left(z_{i t}\right)\right]}$. Berdasarkan arrangement tersebut maka diperoleh model regresi sebagai berikut:

$\log \frac{z_{i t+1}}{z_{i t}}=\zeta \log \frac{\left(1-\tau_{i t+1}\right)}{\left(1-\tau_{i t}\right)}+\eta \log \frac{\left[z_{i t+1}-T_{i t}\left(z_{i t+1}\right)\right]}{\left[z_{i t}-T_{i t}\left(z_{i t}\right)\right]}+\varepsilon$

Dalam model tersebut, dependent variable nya adalah natural $\log$ of income pada tahun $\mathrm{t}+1$ dibagi dengan income pada tahun dasar (base year $\mathrm{t}$ ), dimana tahun $t+1$ adalah satu (1), dua (2), atau tiga (3) tergantung interval tahun yang digunakan. Koefisien variable $\zeta$ menunjukkan compensated elasticity parameter (elasticity of taxable income) dan koefisien $\eta$ adalah income effects parameter. $z$ merupakan pendapatan riil yang dilaporkan dalam SPT pada tahun $t, \tau$ merupakan marginal tax rate pada tahun $t$ and $T(z)$ adalah $\mathrm{PPh}$ terutang.

Dalam penelitian ini, interval 1 tahun digunakan sebagai alternative untuk interval dua atau tiga tahun setelah perubahan tarif pajak. Weber (2011) menyatakan bahwa secara matematis dan empiris, penggunaak interval 1 tahun dapat diterima, khususnya untuk meng-capture respond jangka pendek. Lebih lanjut, hal ini juga memberikan keuntungan bahwa estimasi dapat dianggap berasal dari perubahan tarif pajak karena perubahan pendapatan dalam jangka pendek sulit terjadi (Heim, 2006).

Secara metodologis, isu yang dominan dalam penelitian ini adalah bagaimana mengisolasi respon atas perubahan tarif pajak tanpa campur tangan factor-faktor lain mengingat perubahan respon atau perilaku Wajib Pajak, seringkali disebabkan juga oleh faktor-faktor di luar tarif pajak. Untuk mengatasi hal ini maka Saez, Slemrod and Giertz (2010) menyatakan bahwa untuk menghitung elastisitas pendapatan ini, maka fenomena mean reversion, secular income trend dan endigenity harus diidentifikasi. 


\section{Mean Reversion dan Income Trend}

Mengingat distribusi pendapatan yang dilaporkan dalam SPT biasanya melebar karena pendapatan orang kaya yang makin tinggi disaat yang sama pendapatan orang miskin makin jauh dari mean dan pertumbuhan pendapatan fluktuatif, apabila kita tidak memperhatikan hal tersebut, maka estimasi yang dilakukan akan menjadi bias (Giertz, 2009). Penelitian yang dilakukan (Gruber and Saez, 2002), Giertz (2006), and Weber (2011)) telah mengidentifikasi betapa pentingnya melakukan control atas mean reversion dalam penelitian tentang elastisitas pendapatan.

Mengikuti penelitian-penelitian sebelumnya, dalam mengatasi problem mean reversion maka dilakukan dua Teknik. Teknik ini digunakan untuk menghilangkan bias yang terjadi akibat kemungkinan adanya nonlinearity of income distribution. Mean reversion yang terjadi pada bagian paling bawah distibusi pendapatan diminimalisir dengan hanya memasukkan Wajib Pajak yang memiliki pendapatan minimal Rp25.000.000,- pada tahun dasar 2007 (base year).

Sedangkan untuk mengontrol mean reversion dan tren pendapatan yang tidak terkait dengan perubahan pajak, khususnya atas populasi yang berada pada bagian atas distribusi pendapatan, mengikuti apa yang dilakukan oleh Kopczuk (2005) dan Gruber dan Saez (2002), digunakan 10-spline dari log pendapatan pada tahun dasar, dengan notasi SPLINE $\left(z_{i t}\right)$. Adanya 10 spline ini diharapkan mampu menunjukkan hubungan fungsionalitas hingga level decile antara dependent variable dan the independent variable.

\section{Endogenitas}

Endogenitas menjadi salah satu isu sentral dalam penelitian yang terkait dengan analisis pengaruh pajak terhadap pendapatan. Hal ini terjadi karena elastisitas pendapatan yang diperoleh dengan cara melakukan regresi dari log perubahan penghasilan dan log perubahan net-of tax rate $(1-\tau)$ akan menyebabkan terjadinya endogenitas, apabila tidak menggunakan instrument variable. Tarif pajak merupakan fungsi dari total pendapatan dan 
basis pengenaan pajak, juga merupakan fungsi dari pendapatan. Dengan demikian, marginal tax rate (tarif pajak) juga sangat tergantung dengan besar-kecilnya pendapatan.

Untuk mengestimasi $\zeta$ dan $\eta$ dan mengatasi masalah endogenitas yang muncul karena perubahan net-of-tax rates dan after-tax income akibat dari perubahan pendapatan, penelitian ini menggunakan instrument variables. Gruber and Saez (2002) juga menggunakan instrument variables dalam melakukan estimasi elastisitas pendapatan.

Instrument variable yang digunakan dalam penelitian ini dilakukan sebagai berikut. Variabel $\log \frac{\left(1-\tau_{i t+1}\right)}{\left(1-\tau_{i t}\right)}$ menggunakan instrument variable $\log \frac{\left(1-\tau_{p}\right)}{\left(1-\tau_{i t}\right)}$ dimana notasi $\tau_{p}$ adalah marginal tax rate Wajib Pajak $i$ pada tahun pajak $t+1$. Seluruh pendapatan atau penghasilan dalam kalkulasi ini disesuaikan dnegan tingkat inflasi untuk meminimalkan respon akibat hal lain selain pajak. $^{3}$

Lebih lanjut, variabel $\log \frac{\left[z_{i t+1}-T_{i t}\left(z_{i t+1}\right)\right]}{\left[z_{i t}-T_{i t}\left(z_{i t}\right)\right]}$ pada persamaan 2, yang digunakan untuk meng-capture income shock, juga perlu diberikan instrument variable. Mengingat secara matematis variable tersebut berhubungan dengan error term, mengikuti treatment yang dilakukan Gruber \& Saez (2002), maka variable tersebut menggunakan $\log \frac{\left[z_{i t}-T_{p}\right]}{\left[z_{i t}-T_{i t}\left(z_{i t}\right)\right]}$, sebagai instrument variable, dimana $T_{p}$ adalah $\mathrm{PPh}$ terutang (real tax liability) pada tahun $\mathrm{t}+1$ yang harus dibayar oleh Wajib Pajak apabila penghasilannya tidak berubah secara riil. Instrument ini untuk menegaskan bahwa pendapatan tidak mengalami perubahan, kecuali adanya perubahan tarif pajak.

\section{Mengisolasi Faktor-faktor lainnya}

Selain isu-isu statistik di atas, seperti kita ketahui bahwa Indonesia memiliki tingkat keberagaman yang sangat tinggi, khususnya dalam aspek 
budaya dan ekonomi, dan aspek individu seperti status perkawinan. Pertumbuhan ekonomi di Jawa cenderung lebih mature (tidak terlalu tinggi namun stabil), sedangkan di luar Jawa lebih fluktuatif. Untuk mengakomodasi situasi Indonesia ini maka penelitian ini membuat dummy variable antara lain mars untuk meng-capture perbedaan status perkawinan, 0 untuk yang tidak menikah dan 1 untuk Wajib Pajak yang menikah. Dummy variable CITY dan LOCATION juga digunakan untuk menunjukkan lokasi dan kota-kota di Indonesia, dimana 1 untuk Wajib Pajak yang tinggal di Jakarta (ibu kota negara) dan 0 untuk Wajib Pajak yang tinggal di luar Jakarta. Sedangkan LOCATION digunakan sebagai dummy variabel dengan 1 untuk Wajib Pajak di Pulau Jawa, dan 0 untuk sisanya.

Penelitian ini juga memasukkan dummy variable yang terkait dengan pekerjaan Wajib Pajak untuk meng-capture kemungkinan adanya variasi pendapatan yang diakibatkan oleh perbedaan jenis pekerjaan. Dummy variable $J O B$ digunakan dengan meng-capture hal ini.

Dengan mempertimbangkan hal-hal di atas, maka spesifikasi model regresi yang digunakan dalam penelitian ini sebagai berikut:

$$
\begin{aligned}
\log \left(\frac{z_{i t+1}}{z_{i t}}\right)= & \alpha_{0}+\zeta \log \left[\frac{1-\tau_{i t+1}}{1-\tau_{i t}}\right]+\eta \log \left[\frac{z_{i t+1}-T_{i t+1}\left(z_{i t+1}\right)}{z_{i t}-T_{i t}\left(z_{i t}\right)}\right]+\alpha_{1} \log z_{i t} \\
& +\sum_{k} \alpha_{2 k} \operatorname{mars}_{i t}+\sum_{j} \alpha_{3 j} Y_{E A R_{t}}+\sum_{k} \alpha_{4 k} \operatorname{CITY}_{i t} \\
& +\sum_{k} \alpha_{5 k} \operatorname{LOCATION}_{i t}+\sum_{k} \alpha_{6 k} J O B_{i t}+\sum_{t=1}^{4} \alpha_{4 i} \operatorname{SPLINE}\left(z_{i t}\right) \\
& +\varepsilon_{t}
\end{aligned}
$$

Persamaan regresi tersebut diestimasi dengan menggunakan 2SLS regression dengan $\log \left[\frac{1-\tau_{\mathrm{p}}}{1-\tau_{\mathrm{it}}}\right]$ dan $\log \frac{\left[z_{i t}-T_{p}\right]}{\left[z_{i t}-T_{i t}\left(z_{i t}\right)\right]}$, sebagai instruments variable $\log \left[\frac{1-\tau_{i t+1}}{1-\tau_{i t}}\right]$ dan $\log \left[\frac{z_{i t+1}-T_{i t+1}\left(z_{i t+1}\right)}{z_{i t}-T_{i t}\left(z_{i t}\right)}\right]$. 


\section{Data}

Data yang digunakan dalam penelitian ini merupakan data panel Wajib Pajak Orang Pribadi dari Direktorat Jenderal Pajak untuk tahun pajak 2007 sampai tahun 2010. Data ini merupakan data SPT 1770, dengan data awal yang diperoleh sebanyak 908.247 observasi. Namun tidak seluruh data Wajib Pajak tersebut dapat digunakan karena beberapa hal, misalnya data Wajib Pajak yang tidak lengkap (kurang dari 4 tahun) maka data tersebut didrop.

Hal lainnya adalah apabila penghasilan yang dilaporkan di SPT bernilai negatif atau Wajib Pajak mengalami kerugian dalam usahanya, maka Wajib Pajak ini juga dikeluarkan dari sampel. Hal ini dilakukan untuk menghindari bias yang nantinya akan mengakibatkan kesulitan dalam melakukan generalisasi. Selain itu, pendapatan Wajib Pajak dibawah Rp25 juta juga dikeluarkan dari sampel untuk menghindari mean reversion.

Wajib Pajak yang mengalami perubahan status perkawinannya juga dikeluarkan dari sampel, hal ini dilakukan untuk menghindari adanya perubahan pendapatan kena pajak yang berasal dari factor di luar tarif pajak. Dengan menerapkan beberapa langkah di atas, maka diperoleh sampel sebanyak 32.113 Wajib Pajak atau setara dengan 128.452 observasi.

\section{c. Hasil Penelitian dan Pembahasan}

Analisis dalam penelitian ini menekankan pada perubahan pendapatan dari tahun ke tahun. Dependent variable dalam penelitian ini adalah log pertumbuhan pendapatan (penghasilan broto maupun penghasilan neto). Estimasi dilakukan dengan menggunakan two-stage least square (2SLS) dengan instrument variable command STATA xtivreg, ketika melakukan estimasi untuk model yang menggunakan interval satu tahun dan dua, serta ivreg command STATA untuk estimasi model interval tiga tahun.

\section{1) Analisis Data dengan Interval 1 Tahun (Short Run Analysis)}

Dalam analisis yang menggunakan interval data 1 tahun, pendapatan tahun 2007 dibandingkan dengan pendapatan tahun 2008, dan 
pendapatan tahun 2008 dibandingkan dengan 2009, begitu seterusnya. Estimasi awal dilakukan dengan menampilkan spesifikasi model regresi yang paling sederhana, tanpa control apapun. Hasil regresi menunjukkan estimasi yang tidak sesuai dengan yang diharapkan. Koefisien $\zeta$ memberikan tanda negative (wrong sign of estimations) meskipun telah digunakan dua definisi pendapatan (penghasilan kena pajak dan penghasilan bersih). Besaran elastisitas pendapatan adalah -2.202 bila menggunakan definisi penghasilan kena pajak dan -1.375 untuk elastisitas pendapatan (dengan definisi pendapatan berdasarkan penghasilan bersih pada SPT). Kedua koefisien tersebut signifikan pada level 99\% secara statistic. Namun karena bertanda negatif maka perlu analisis lebih lanjut secara hati-hati.

Selanjutnya estimasi kembali dilakukan namun dengan memasukkan beberapa control variable, yaitu log base year's income (pendapatan Wajib Pajak tahun dasar $)\left(z_{i t}\right)$. Hasilnya, koefisien $\zeta$ masih memberikan tanda negative, namun magnitude-nya berkurang menjadi -1.375 (untuk definisi pendapatan dengan menggunakan penghasilan kena pajak) dan 0.986 (untuk definisi pendapatan dengan penghasilan neto). Kedua koefisien tersebut signifikan secara statistic dengan level of confidence 99\%. Meskipun koefisiennya masih menunjukkan tanda yang tidak diharapkan, namun dari dua hasil estimasi ini menunjukkan bahwa penting untuk melakukan control terhadap pendapatan. Dan pada regresi yang terakhir, terlihat bahwa dengan mengontrol pendapatan (penghasilan) terjadi perubahan nilai koefisien secara signifikan.

Selanjutnya Penulis menggunakan full specification sebagaimana persamaan regresi nomor $3 \mathrm{di}$ atas. Sepuluh spline untuk mengkontrol pendapatan digunakan, begitu juga dengan dummy variable lainnya. Hasilnya, besaran elastisitas pendapatan meningkat drastis dan bernilai positif, searah dengan nilai yang diharapkan sebagaimana temuan pada penelitian-penelitian sebelumnya. Hasil estimasi ini menunjukkan elastisitas sebesar 0.302 dengan standard deviasi sebesar 0.062 
(penghasilan bersih) dan 0.368 dengan standard deviasi 0.071 untuk penghasilan kena pajak. Kedua koefisien ini signifikan secara statistik pada level of confidence $99 \%$.

Dari estimasi ini, dapat diperoleh kesimpulan bahwa peran control terhadap pendapatan sangat penting. Variabel 10 spline dari pendapatan, terbukti efektif untuk mengisolasi adanya secular trend of income.

2) Analisis Data dengan Interval 2 Tahun dan Interval 3 Tahun (Medium Run Analysis)

Dalam analisis yang menggunakan interval 2 tahun, data di-set dengan basis perbedaan 2 tahun. Data pendapatan tahun 2007 dipasangkan dengan data pendapatan 2009, begitu seterusnya. Tujuan dari estimasi interval 2 tahun ini adalah untuk melihat respon Wajib Pajak dalam jangka waktu medium term. Esmimasi elastisitas pendapatan menggunakan xtivreg command dengan menggunakan STATA.

Dengan menerapkan model regresi dalam estimasi, diperoleh temuan bahwa seluruh spesifikasi menunjukkan hasil yang tidak signifikan, secara statistic. Bahkan ketika level of confidence diset $90 \%$, hasil regresi tetap menunjukkan hal tersebut. Artinya kita tidak bisa menolak null hypothesis bahwa koefisien bukan nol. Hasil ini menunjukkan bahwa elastisitas pendapatan (untuk semua definisi pendapatan) bernilai nol atau mendekati nol.

\section{3) Analisis Data dengan Interval 3 Tahun}

Analisis selanjutnya, data regresi menggunakan interval 3 tahun. Data pendapatan tahun 2007 dibandingkan dengan data pendapatan Wajib Pajak tahun pajak 2010. Dengan pendekatan ini maka jumlah sampel data panel turun drastic sehingga kurang tepat apabila tetap menggunakan panel data analysis. Akhirnya Peneliti menggunakan analisis cross-section regression dnegan tetap menggunakan ivreg command dengan STATA. 
Hasil regresi menunjukkan bahwa seluruh spesifikasi model regress menghasilkan koefisien yang tidak signifikan secara statistic. Artinya kita tidak bisa menolak null hypothesis bahwa koefisien bukan nol. Hasil ini menunjukkan bahwa elastisitas pendapatan (untuk semua definisi pendapatan) bernilai nol atau mendekati nol. Lebih detail, penelitian ini memperoleh hasil bahwa koefisien elastisitas pendapatan sebesar 0.029, untuk definisi pendapatan penghasilan kena pajak. Sedangkan apabila menggunakan definisi pendapatan adalah penghasilan bersih maka elastisitasnya menjadi -0.086. dan, keduanya secara statistic tidak signifikan. Dengan demikian dapat dikatakan bahwa besaran elastisitas pendapatan untuk semua jenis definisi pendapatan adalah mendekati nol atau sangat kecil.

\section{Pembahasan}

Untuk memudahkan pembahasan, di bawah ini disajikan rangkuman hasil estimasi sebagai berikut. Dibawah ini disajikan rangkuman estimasiestimasi yang telah dilakukan.

Elastisitas Pendapatan

\begin{tabular}{|c|l|c|c|}
\hline No & \multicolumn{1}{|c|}{ Uraian } & $\begin{array}{c}\text { Penghasilan Kena } \\
\text { Pajak (Taxable Income) }\end{array}$ & $\begin{array}{c}\text { Penghasilan bersih } \\
\text { (Net Income) }\end{array}$ \\
\hline 1 & Interval 1 tahun & 0.368 & 0.302 \\
\hline 2 & Interval 2 tahun & -0.003 & 0.059 \\
\hline 3 & Interval 3 tahun & 0.029 & -0.086 \\
\hline
\end{tabular}

Sumber: Hasil regresi

Dari hasil estimasi di atas, setidaknya terdapat tiga isu yang akan dibahas pada pokok bahasan berikut ini. Pertama adalah isu tentang besarkecilnya elastisitas pendapatan sebagai respon Wajib Pajak atas adanya penurunan tarif pajak. Isu kedua adalah tentang bagaimana menginterpretasikan besaran elastisitas pendapatan tersebut. Dan yang 
terakhir adalah tentang perbedaan elastisitas pada periode short run dan medium run.

Pertama. Bila kita membandingkan dengan penelitian-penelitian yang terkait dengan bagaimana respon atau perilaku Wajib Pajak tatkala terdapat suatu penurunan tarif pajak maka temuan dalam penelitian ini memunjukkan konsistensi dengan penelitian-penelitian tersebut. Besaran elastisitas pendapatan di Indonesia masuk dalam kategori sebagaimana yang disebutkan oleh Holmlund dan Soderstrom (2007) sebagai "preferred estimates," yaitu elastisitas yang berada dalam range 0.2 sampai dengan 0.5 . Dengan magnitude elastisitas sebesar 0.237 hingga 0.368 , tergantung definisi pendapatan yang digunakan, respon Wajib Pajak di Indonesia masuk dalam preferred estimates.

Besaran elastisitas pendapatan di Indonesia ini juga mendekati "consensus value" sebagai istilah yang diperkenalkan oleh Gierzt (2004) dan Saez, Slemrod dan Giertz (2010), dimana besaran "consensus value" ini adalah 0.4. Temuan dalam penelitian ini menegaskan bahwa karakteristik respon Wajib Pajak terhadap penurunan tarif pajak di Indonesia dapat dibandingkan atau bahkan mirip dengan respon atau perilaku Wajib Pajak di negara lain. Dengan besaran atau magnitude elastisitas sebesar 0.237 hingga 0.368 , tergantung definisi pendapatan yang digunakan, respon Wajib Pajak di Indonesia dapat dikatakan moderat.

Kedua. Besaran atau magnitude elastisitas yang bernilai positif sebesar 0.237 hingga 0.368 memberikan signal yang baik bagi pemerintah bahwa kebijakan pemerintah untuk menurunkan tarif pajak, terbukti mampu medorong Wajib Pajak melaporkan pendapatan dalam SPT lebih tinggi. Berdasarkan temuan ini maka setiap $1 \%$ penurunan tarif pajak di Indonesia, maka Wajib Pajak punya kecenderungan untuk melaporkan penghasilannya 0.2\%-0.3\% lebih besar dari pendapatan semula apabila tidak ada kebijakan penurunan tarif pajak.

Perbedaan besaran elastisitas yang terjadi ketika menggunakan definisi pendapatan yang berbeda menunjukkan bahwa terdapat perbedaan antara 
respon mekanikal dan respon perilaku. Gruber dan Saez (2002) menyatakan bahwa terdapat dua lasam mengapa terjadi perbedaan magnitude elastisitas pendapatan ketika definisi pendapatan yang berbeda digunakan, yaitu mechanical dan behavioral responses. Menurut Gruber dan Saez (2002), respon mekanikal bertanggung jawab menjelaskan bahwa penghasilan bersih yang tinggi otomatis akan menghasilkan respon yang lebih kecil karena Wajib Pajak dengan income base yang sudah tinggi maka respon penurunan tarif akan berdapat tidak begitu besar terhadap peningkatan nilai penghasilan yang dilaporkan.

Lain halnya dengan respon perilaku, dimana dengan perhitungan penghasilan kena pajak (taxable income) didalamnya terdapat beberapa factor pengurang pajak. seperti PTKP. Dalam hal ini Wajib Pajak dapat memilih antar menggunaka PTKP maksimal dengan menambah jumlah tanggungan misalnya, atau tidak, sebelum menentukan besar-kecilnya pajak yang akan dilaporkan ke otoritas pajak.

Ketiga. Kecilnya magnitude elastisitas pendapatan dalam interval waktu 2 dan 3 tahun ini menunjukkan bahwa adanya kemungkinan terjadinya income shifting. Wajib Pajak mungkin memberikan respon positif ketika penurunan tarif diumumkan dalam upayanya mengoptimalkan kesempatan untuk mengambil keuntungan ekonomis sebesar-besarnya. Dan melupakannya setelah keuntungan tersebut didapat. Setelah mempelajari bagaimana otoritas pajak bekerja dalam menangani Wajib Pajaknya, Wajib Pajak bisa saja berusaha mencari opsi-opsi efisiensi lainnya, seperti melakukan tax planning atau income shifting. Atau bisa jadi Wajib Pajak menunda-nunda pelaporan penghasilannya karena menunggu-nunggu kebijakan perpajakan yang baru, misalnya adanya rencana pemerintah untuk melakukan tax amnesty. Perilaku ini tentu saja akan mengakibatkan jumlah penghasilan yang dilaporkan di SPT mengalami stagnasi atau mungkin malah mengalami penurunan. Hal ini merupakan salah satu factor untuk menjelaskan mengapa dalam jangka waktu medium, elastisitas pendapatan di Indonesia mengalami penurunan atau bahkan mendekati nol. 
Temuan ini sesuai dengan hasil penelitian yang dilakukan oleh Goolsbee (2000). Dalam studinya, Goolsbee menemukan bahwa elastisitas pendapatan bernilai positif dan lebih dari nol dalam jangka pendek, namun mendekati nol dalam jangka Panjang. Kemudian Goolsbee juga mengemukakan bahwa kemungkinan hal tersebut terjadi karena adanya income shifting. Hal yang sama juga ditemukan oleh Heim (2006) bahwa Wajib Pajak terus berupaya melakukan shiftting pendapatan melalui deductions atau memaksimalkan unsur pengurang pajak dan hal-hal yang dikecualikan sebagai objek pajak, atau yang disebut sebagai bagian dari skema tax planning. Lebih lanjut dia juga menambahkan bahwa dalam jangka panjang, efek dari adanya perubahan tarif ini makan semakin mengecil.

Selain argumentasi di atas, hal lainnya yang menyebabkan penurunan elastisitas pendapatan pada medium term adalah fenomena myopic atau perubahan prefensi atau perhatian Wajib Pajak karena terdapat hal-hal lain yang lebih besar. Sebagaimana diketahui bahwa setahu setelah tax reform 2008, terdadi skandal korupsi yang melibatkan beberapa petugas pajak di Indonesia. Isu ini sempat menjadi kehebohan tersendiri dan membuat ototritas pajak mengalami penurunan trust. Adanya isu yang bersifat negatif ini bisa jadi membuat Wajib Pajak enggan membayar pajak, mengurangi atau membuat laporan perhitungan pajaknya dalam SPT menjadi lebih kecil, sebagai ungkapan protes. Hal ini membuktikan apa yang dikatakan oleh Slemrot bahwa elastisitas pendapatan bukan merupakan parameter yang "unchanged", sebaliknya bahwa elastisitas pendapatan merupakan parameter yang masih dapat dipengaruhi oleh hal-hal atau kebijakankebijakan pemerintah lainnya. Dengan demikian, terdapat ruang yang lebar bagi pemerintah bahwa apabila pemerintah ingin mendorong Wajib Pajak supaya melaporkan pajaknya lebih besar, maka pemerintah dapat dibuat kebijakan-kebijakan lain, tidak melulu hanya dengan melakukan penurunan tarif pajak. 


\section{SIMPULAN}

Tujuan utama penelitian ini adalah mengidentifikasi nilai elastisitas pendapatan dengan memanfaatkan adanya penurunan tarif pajak melalui Reformasi Perpajakan Tahun 2008. Reformasi Perpajakan Tahun 2008 sangat menarik untuk diteliti karena menyediakan kesempatan untuk melakukan natural experiments atas suatu kebijakan. Dua fitur utama dalam reformasi ini, yaitu adanya penurunan tarif dan penyederhanaan jumlah lapisan penghasilan, menjadi hal yang menarik perhatian banyak orang, khususnya para Wajib Pajak sehingga menjadi momentum yang tepat untuk melihat bagaimana reaksi atau respon Wajib Pajak terhadap kebijakan tersebut.

Dengan menggunakan data panel sebelum dan setelah adanya reformasi perpajakan tersebut, diperoleh koefisien elastisitas pendapatan akibat adanya penurunan tarif pajak sebesar 0.302-0.368 tergantung definisi pendapatan yang digunakan. Temuan ini mengkonfirmasi argumentasi yang selama ini berkembang bahwa dengan adanya penurunan tarif pajak maka akan meng-encourage Wajib Pajak untuk menaikkan reported income dalam SPT. Berdasarkan temuan ini maka setiap $1 \%$ penurunan tarif pajak di Indonesia, maka Wajib Pajak punya kecenderungan untuk melaporkan penghasilannya $0.2 \%-0.3 \%$ lebih besar dari pendapatan semula apabila tidak ada kebijakan penurunan tarif pajak.

Penelitian ini juga mendapati realitas bahwa perhitungan estimasi ini sangat tergantung bagaimana tren pendapatan dikelola secara statistik. Tanpa meng-control adanya secular income trend, estimasi menghasilkan koefisien yang bernilai negatif. Namun ketika variable pendapatan, yaitu penghasilan kena pajak, di-treatment dengan menggunaka 10 spline, besaran atau koefisien elastisitas pendapatan menjadi bernilai positif dan sesuai sign yang diharapkan dan berada pada kisaran nilai yang disebut oleh Saez, Slemrod dan Giertz (2010) sebagai “concensus value".

Namun dalam analisis medium term, yaitu dengan menggunakan data interval 2 tahun dan 3 tahun, penelitian menemukan fakta bahwa respon 
Wajib Pajak terhadap adanya perubahan (penurunan) tarif $\mathrm{PPh}$ mendekati "nol”. Hal ini menegaskan apa yang disebutkan oleh Slemrod (2001) bahwa "that the magnitude of reported income elasticity is not an unchanged parameter; indeed, it is subject of government policy. Bahwa elastisitas pendapatan dalam jangka menengah yang mendekati nol bisa saja terjadi karena hal-hal lainnya. Argumentasi pertama atas fenomena tersebut adalah adanya fenomena income shifting yang dilakukan oleh Wajib Pajak sebagimana dikatakan oleh Goolsbee (2000). Dalam perspektif Wajib Pajak, pembayaran pajak merupakan beban yang akan mengurangi laba atau profit. Tujuan dari bisnis adalah meningkatkan profit setinggi-tingginya salah satunya dengan meminimalkan beban. Dan salah satu beban yang dapat dikurangi pembayarannya adalah beban pajak, yang biasa dilakukan melalui skema tax planning.

Penyebab kedua dari fenomena tersebut adalah adanya kemungkinan perubahan preferensi Wajib Pajak dalam jangka menengah (myiopic). Dalam jangka menengah, banyak hal yang terjadi dan menjadi isu nasional. Pada tahun 2009, terjadi skandal besar tentang korupsi yang melibatkan petugas pajak. Isu ini sempat menjadi kehebohan dan membuat ototritas pajak mengalami penurunan trust. Adanya isu yang bersifat negative ini bisa jadi membuat Wajib Pajak mengurangi atau membuat laporan perhitungan pajaknya dalam SPT menjadi lebih kecil sebagai ungkapan protes. Jadi sebagaimana yang dikatakan oleh Slemrot bahwa besaran atau koefisien elastisitas pendapatan bukan merupakan parameter yang "unchanged" dengan demikian, masih terdapat ruang bagi pemerintah untuk melakukan peningkatan reported income dalam SPT melalui kebijakan-kebijakan pajak yang lain. 


\section{REFERENSI}

Abimanyu, Anggito and Andie Megantara. 2009. Era Baru Kebijakan Fiskal: Pemikiran, Konsep dan Implementasi. Jakarta: Penerbit Buku Kompas.

Acock, Alan C. 2006. A Gentle Introduction to Stata. Stata Press.

Aris, Ahmad. 2010. "ADB: Sistem Pajak Indonesia Terlalu Rumit." http://www.ipotnews.com/index (as dated May 7, 2012).

Auten, Gerald and Robert Carroll. 1999. The Effect of Income Taxes on Household Behavior. Review of Economics and Statistics, 81(4): 681-693.

Baum, Christopher F. 2006. An Introduction to Modern Econometrics Using Stata. Texas: Stata Press.

Blomquist, Sören and Håkan Selin. 2010. Hourly Wage Rate and Taxable Labor Income Responsiveness to Changes in Marginal Tax Rates. Journal of Public Economics, 94: 878-889.

Budi Suryana, Anandita. 2010. “Jebakan sunset policy?" http://www.hananta.com/uhy/published/public/Jebakan-sunsetpolicy? (as date of May, 10, 2010).

Carroll, Robert. 1998. Do Taxpayers Really Respond to Changes in Tax Rates? Evidence from the 1993 Tax Act. OTA Working Paper 79.

Chetty, Raj. 2008. Is the Taxable Income Elasticity Sufficient to Calculate Deadweight Loss? The Implications of Evasion and Avoidance. NBER. http:// www.economics.harvard.edu.

Claus, Iris, Creedy, John and Teng, Josh. 2010. The Elasticity of Taxable Income in New Zealand. CAMA Working Paper No. 21/2010. Available at SSRN: http://ssrn.com/abstract=1668209.

Dahlby, Bev. 2008. The Marginal Cost of Public Funds, Theory and Applications. The MIT Press.

Devore, Jay L. 2004. Probability and Statistics for Engineering and the Sciences, seventh edition. Cengange Learning. 
Djumena, Erlangga. 2011. "5,89 Juta Wajib Pajak Tak Patuh," http://bisniskeuangan.kompas.com (as dated May 7, 2012).

El Hida, Ramdhania. 2010. "Dirjen Pajak Jelaskan Soal Gayus ke DPR," detikFinance. http://finance.detik.com/read/2010/04/06/153252/1333146/4/ dirjenpajak -jelaskan-soal-gayus-ke-dpr-rabu-pukul-1400-wib (cited May, $18,2012)$.

Feldstein, Martin. 1995. The Effect of Marginal Tax Rates on Taxable Income: a Panel Study of the 1986 Tax Reform Act. Journal of Political Economy, Vol. 103, No. 3.

Feldstein, Martin. 2006. The effects of taxes on efficiency and growth. NBER Working Paper No. 12201.

Feldstein, Martin. 1999. Tax Avoidance and the Deadweight Loss of the Income Tax. Review of Economics and Statistics, 81(4): 674-680.

Fernandez, Camila Nino. 2010. The Elasticity of Taxable Income: The Cases of Chile And Colombia. Universite de la Mediterranee. Marseille, France.

Giertz, Seth. 2004. Recent Literature on Taxable-Income Elasticities. Technical Paper 2004-16. Congressional Budget Office. Washington D.C. www.cbo.gov/ftpdocs/60xx/doc6028/2004- 16.pdf.

Giertz, Seth. 2004. Recent Literature on Taxable-Income Elasticities. Paper 2004-16. Tax Analysis Division of U.S Congressional Budget Office, Washington DC,

Giertz, Seth. 2005. Sensitivity analysis of the elasticity of taxable income. CBO Working Paper 2005-01. Congressional Budget Office. Washington D.C. (updated 2008).

Giertz, Seth. 2007. The Elasticity of Taxable Income over the 1980s and 1990s. National Tax Journal, 60(4): 743-768.

Goolsbee, Austan. 2000. What Happens When You Tax the Rich? Evidence from Executive Compensation. Journal of Political Economy, Vol. 108, No. 2, pp. 352-378. 
Gruber, Jonathan and Emmanuel Saez. 2002. The Elasticity of Taxable Income: Evidence and Implications. Journal of Public Economics, 84: $1-32$.

Gujarati, Damodar N. 1995. Basic Econometrics, 3rd Ed. New York: McGraw-Hill.

Heij, Christiaan, Paul de Boer, Philip Franses, Teun Kloek, Herman K. van Dijk. 2004 Econometric Methods with Applications in Business and Economics. Oxford University Press.

Holmlund, Bertil and Martin Söderström. 2007. Estimating Income Responses to Tax Changes: A Dynamic Panel Data Approach. Discussion Paper Series of Institute for the Study of Labor.

http://www.pajak.go.id/statistic (as date March, 21, 2012).

James, Simon and Christopher Nobes. 1998. The Economics of Taxation, Principles, Policy and Practice. Prentice Hall Europe.

Khumaini, Anwar. 2010. “Gerakan Boikot Bayar Pajak di FB Capai 20 Ribu Pendukung," Detiknews, http://news.detik.com/read/2010/03/27/040352/ 1326518/10/gerakan-boikot-bayar-pajak-di-fb-capai-20-ribupendukung (cited May, 18, 2012).

Kopczuk, Wojciech. 2005. Tax Bases, Tax Rates and the Elasticity of Reported Income. Journal of Public Economics, 89(11-12): 20932119.

Linsey, Lawrence B. 1987. Individual Taxpayers Response to Tax Cuts: 1982-1984. Journal of Public Economics 33.

Rochjadi, Achmad, and Leuthold, Jane H. 1994. The Effect of Taxation on Labor Supply in a Developing Country: Evidence from Crosssectional Data. Economic Development and Cultural Change. The University of Chicago Press, Vol. 42, No. 2.

Saez, Emmanuel, Joel Slemrod and Seth H. Giertz. 2010. The Elasticity of Taxable Income with Respect to Marginal Tax Rates: A Critical Review. NBER. 
Saez, Emmanuel. 2001. Using Elasticities to Derive Optimal Income Tax Rates. Review of Economic Studies, 68: 205-229.

Saez, Emmanuel. 2004. Reported Incomes and Marginal Tax Rates, 19602000: Evidence and Policy Implications. in James Poterba, ed., Tax Policy and the Economy, 18: 117-174.

Saez, Emmanuel. 2004b. The Optimal Treatment of Tax Expenditures. Journal of Public Economics, 88(12): 2657-2684.

Salanie, Bernard. 2002. The Economics of Taxation. The MIT Press, Cambridge, Massachusetts.

Slemrod, Joel and Wojciech Kopczuk. 2001. The Optimal Elasticity of Taxable Income. Journal of Public Economics, 84(1): 91-112.

Snyder, Christopher and Walter Nicholson. 2010. Microeconomic Theory Basic Principles and Extensions. International Edition.

Stiglizt, Joseph E. 1999. Economics of The Public Sector Third Edition. WW Norton \& Company.

Thomas, Alastair. 2007. Taxable Income Elasticities and The Deadweight Cost of Taxation in New Zealand. Inland Revenue Department.

Trandel, Gregory A. 2008. Making the Indifference-Curve Approach to Excess Burden More Understandable. Department of Economics, University of Georgia.

Weber, Caroline. 2010. Obtaining a Consistent Parameter of the Elasticity of Taxable Income Using Difference-in-Differences. Working Paper.

Weber, Caroline. 2011. Obtaining a Consistent Parameter of the Elasticity of Taxable Income Using Difference-in-Differences.

Witczak, Daniela and Peter Gottfried. 2009. The Responses of Taxable Income induced by Tax Cuts-Empirical Evidence from the German Taxpayer Panel. IAW Diskussionspapiere No. 57 November 2009. 